\title{
Circulation of Private Notes during a Currency Shortage*
}

\author{
March $2^{\text {nd }}, 2005$
}

Xavier Cuadras-Morató

\author{
Department of Economics and Business \\ Universitat Pompeu Fabra \\ Ramon Trias Fargas, 25-27 \\ 08005 Barcelona \\ Spain
}

Phone: 34935422606

Fax: 34935421746

e-mail: xavier.cuadras@upf.edu

JEL classfication: E40, D83

\footnotetext{
* This research was initiated while I was visiting the Department of Economics at the University of Pennsylvania during the year 2002-03. My thanks go to the members of the department and, above all, to Randall Wright for many helpful comments. A preliminary version of the paper was presented at the workshop "Money and Markets" organized by FORUM at the Université de Paris X (Nanterre) in September 2003, the ASSET Annual Conference (Barcelona, November 2004) and the Simposio de Análisis Económico (Pamplona, December 2004).
} 


\begin{abstract}
This paper provides a search theoretical model that captures two phenomena that have characterized several episodes of monetary history: currency shortages and the circulation of privately issued notes. As usual in these models, the media of exchange are determined as part of the equilibrium. We characterize all the different equilibria and specify the conditions under which there is a currency shortage and/or privately issued notes are used as means of payment. There is multiplicity of equilibria for the entire parameter space, but there always exist an equilibrium in which notes circulate, either alone or together with coins. Hence, credit is a self-fulfilling phenomenon that depends on the beliefs of agents about the acceptability and future repayment of notes. The degree of circulation of coins depends on two crucial parameters, the intrinsic utility of holding coins and the extent with which it is possible to find exchange opportunities in the market.
\end{abstract}

Keywords: money, notes, search, credit, currency shortage. 


\section{Introduction}

Economic historians have reported several episodes in which notes issued by individuals circulated and were generally accepted as payment for commercial transactions in such a way that they acted as substitutes of other media of exchange such as metal coins or notes issued by banks. Ashton (1945), for instance, analyzes the circulation of bills of exchange in Lancashire between 1790 and $1830 .{ }^{1}$ He reports that "the bill had become more than a security for payment. The drawer very often passed it on to meet obligations of his own, and those who received it, in their turn, did the same. The bill was now a substitute for money" (Ashton, 1945, p.25). Cuadras-Morató and Rosés (1998) analyze a similar episode in Catalonia between 1844 and 1874. Butlin (1953) reports a different experience, this time located in Australia at the beginning of the nineteenth century. Promissory notes were issued by individuals and circulated widely. He reports that "from the simple expedient of settling debts with promissory notes grew, in the first decade of the nineteenth century, the practice of regular issue by all and sundry of small notes, heterogeneous in form and often disreputable" (Butlin, 1953, p.4). These promissory notes were written on any handy scrap of paper and accepted in the most casual manner and once issued remained in circulation for great lengths of time (see Butlin 1953, p.27). Notes were generally drawn in terms of money, although not necessarily (they could be payable in wheat or maize, for instance). Very

\footnotetext{
${ }^{1}$ See also Schumpeter (1986), p.695 and Cameron (1967), chapter 2.
} 
often they were accepted only at a discount. ${ }^{2}$ Needless to say, the circulation of this type of promissory notes was the origin of many frauds and litigations. ${ }^{3}$

There seems to be ample evidence that these private notes and other documents widely circulated because of the lack of better alternatives, especially metal coins and banknotes. In many cases gold and silver did not circulate because they were exported to finance international trade (this seems to be a common circumstance of many of these episodes) or used for purposes other than internal exchanges. Ashton (1945), for instance, states that bills of exchange circulated because of a need that arose "from an inadequate flow of silver from the Mint and from a poorly organized system of distribution: when the state fails in the elementary function of providing a proper supply of legal tender the community seeks to create a currency of its own" (Ashton, 1945, p.26). In Australia the extinction of this practice did not happen "until the 1830's, when bank notes and English coins were in common use and cheque payments an everyday experience" (Butlin, 1953, p.68). In other words, once the monetary system was able to provide with satisfactory alternative means of payment, it was no longer necessary to accept promissory notes and, consequently, they were not issued any more. ${ }^{456}$

\footnotetext{
${ }^{2}$ Examples of discounts reported in Butlin (1953), p. 97, for the period 1811-1815 have values between $20 \%$ and $50 \%$.

${ }^{3}$ A similar case is described in Sargent and Velde (2002), which refers to privately issued convertible tokens in England during the XVII and XVIII centuries and before the nationalization of the token coinage in 1817 (p. 261).

${ }^{4}$ See also Cuadras-Morató and Rosés (1998).

${ }^{5}$ Hanson (1979) is another illustration of the problem of shortages of specie, this time in Colonial America. He argues that the issue of notes by private merchants was one of the solutions to the problem suggested by contemporary observers.

${ }^{6}$ Murphy (1978) describes a more recent episode in Ireland where banks closed several times between 1966 and 1976 and personal checks started circulating as media of exchange.
} 
This paper presents a search theoretical model that analyzes the coexistence and circulation of commodity money (metal coins) and credit (promissory notes) as means of payment. As it is customary in this type of models, all agents are specialized and must exchange with others in order to consume. In this particular model, agents have access to the possibility of issuing notes and buy consumption goods on credit. Once issued, these notes may circulate in the economy as media of exchange. Alternatively, agents may buy goods and pay for them with metal coins. We model these coins as intrinsically valuable (that is, money holders get utility out of the possession of coins). Obviously this should not be taken literally, as it is only meant to be a shortcut that allows us to capture the fact that coins may have alternative uses to paying for goods produced in the economy. For instance, in accordance with the historical episodes we have mentioned above, one could assume that coins could be used to pay for an imported consumption good produced by agents situated outside the economy.

The search theoretical model of money seems particularly appropriate to analyze the issues of currency shortages and circulation of notes because it formalizes explicitly the trade frictions that motivate the emergence of different media of exchange in equilibrium. Furthermore, this modeling strategy has become standard in Monetary Economics and it seems important that more research is devoted to apply it to study specific historical events such as the one we are dealing with.

One of the main purposes of the paper is to characterize all the existing equilibria of the model, which imply different degrees of circulation of coins and notes. Several results are worth mentioning. First, for some values of the parameters it will be the case that agents who hold coins do not want to spend them buying domestic goods 
and, consequently, there will be a shortage in the circulation of these coins. The key parameters to analyze will be the utility that money holders derive from possessing coins and the extent of exchange opportunities that can be found in the market. One of the main results of the model states that the larger is the utility that money holders derive from possessing coins, the more difficult will be their circulation and, consequently, the higher will be the likelihood that notes are the only possible means of exchange in the economy. For a given level of utility of holding money, however, the shortage of coins will depend on the amount of trade opportunities in the economy. One the one hand, if money is relatively valuable, money holders will keep it unless the trade opportunities they get by buying other assets, such as notes, are big enough. On the other hand, if money is of little value and exchange opportunities are relatively scarce, money holders will tend to be not very selective when they spend their coins because they need to take advantage of the few exchange opportunities they encounter.

Second, for all values of the parameters there exists some equilibrium in which notes circulate. This confirms that credit is a self-fulfilling phenomenon. After all, the existence and circulation of credit depends on the fact that agents believe that it will be accepted by others and, eventually, repaid. Third, we show that the existence of credit is welfare enhancing for almost all values of the parameters. This is a natural result, given that credit in this model is a very efficient mechanism to overcome the trade frictions that characterize the economy.

Formally, the model is based on previous developments of the search theoretic model of money. Shi (1996) is one of the first contributions to the joint analysis of money and credit in the context of search theory. There are two main differences with 
our analysis worth mentioning. First, the paper deals with fiat money (we consider commodity money instead), which makes it rather unsuitable to study currency shortages. Second, specific assumptions to simplify the model preclude the analysis of what it is one of our main concerns, namely, the circulation of promissory notes as means of payment in the economy. $\mathrm{Li}$ (2001) is specifically concerned with circulating notes in the context of a model with fiat money. Nevertheless, some of the results of the paper are a bit unsatisfactory from our point of view. In particular, it is necessary that a relatively large proportion of agents are holding money in order to have a monetary equilibrium with circulating notes. This is due to the fact that money is assumed to be the only way to repay debts in the economy. Also, the analysis in $\mathrm{Li}$ (2001) does not provide with general conditions for the existence of the main equilibrium and relies on numerical examples. We assume that debts can be repaid with notes, which simplifies the model a great deal and give us substantially different results. In our model the emergence of credit depends only on beliefs, which means that there exist equilibria with credit for the entire relevant parameter space. The nature of those equilibria differs in the degree of circulation of metal coins, which will depend on the values of the parameters, namely, the intrinsic value of money, the time preference of individuals, and the extent with which agents could meet exchange opportunities in the market. Our modeling of commodity money (coins) shares many features with the model presented in Velde, Weber and Wright (1999). In particular, we take from them the assumption of making money intrinsically valuable as a shortcut of a more sophisticated story that can justify shortages of coins. Wallace and Zhou (1997) study similar historical episodes, although they concentrate on the question of shortage of coins for certain transactions due to indivisibilities. Although we also assume that coins are indivisible, we focus on 
the study of the possibility that private notes circulate as means of alleviating currency shortages. $^{7}$

The rest of the paper is organized as follows. The next section describes the basic model. Section 3 presents the main results on existence of equilibria. Section 4 discusses welfare issues and Section 5 concludes with a short summary of the results and a few suggestions for future research.

\section{The model}

Apart from a few changes in the environment that will be explained in detail below, we work with the same model as in Li (2001).

2.1. The Environment. Time is discrete and the horizon is infinite. There are $N \geq 3$ distinct perishable and perfectly divisible consumption goods. There is a $[0,1]$ continuum of infinitely lived agents, who are specialized in production and consumption with the following pattern: agents of type $i$ consume good $i$ and produce good $i+1$ (modulo $N$ ). The number of agents of each type is identical. This pattern of specialization means that consumption will not be possible without trade and direct barter is not feasible. Consumption of $q$ units of good $i$ yields utility $u(q)$ to type $i$ agents, while production of the same amount of units of good $i+1$ inflicts them with a cost of $c(q)$ in terms of disutility. Without loss of generality, we normalize $c(q)=q$. The

\footnotetext{
${ }^{7}$ The issues of circulation of notes and currency are also studied in a different category of models, characterized by private information, spatial separation and limited communication. Examples of this
} 
utility function is defined in the interval $[0, \infty)$. It is strictly increasing and twice differentiable. Also, $u(0)=0, u^{\prime}(0)=\infty$, and $u^{\prime \prime}(q)<0$ for all $q>0$. There is a $q^{*}>0$ such that $u\left(q^{*}\right)=q^{*}$. Agents maximize their lifetime expected discounted utility (with a common discount rate $r$ ).

Each period of time is divided into two different subperiods. The first is called the production subperiod. This is the time during which agents randomly meet other agents, have access to their production technology and make their exchange decisions. Goods produced during this subperiod must be consumed then or otherwise they perish. After this, it comes the repayment subperiod. During this subperiod no agent can produce but the agents who issued a note at some previous period are able to make contact with the agent who is holding that note (details about the issue and circulation of these notes are provided in section 2.2). It will be assumed that the repayment subperiod takes place immediately after the first subperiod and is extremely short and, hence, we can ignore discounting between both subperiods.

There is not a centralized trading place for goods in this economy and, during the production subperiod, agents randomly search and meet in pairs to carry out exchanges of goods and assets. Each period agents encounter potential trading partners according to a Poisson process with constant arrival rate $\beta>0$. They can perfectly observe all agents' type and inventory holdings (that is, whether they are holding nothing or some asset). Given this, agents will make decisions about production, exchange of goods and assets, and consumption.

kind of models are Townsend and Wallace (1987), Bernhardt (1989), Townsend (1989), and Bullard and Smith (2003a). 
2.2. Money and Credit. There are potentially two different assets in this economy, money and credit, both perfectly storable. For tractability we will assume, first, that assets are indivisible ${ }^{8}$ and, second, that individuals cannot hold more than one unit of either asset. In contrast with the setting in Li (2001), money in this model is commodity money (metal coins, for instance). We shall assume that, although money cannot be directly consumed by anyone, agents who hold money enjoy a stream of direct utility $\gamma(\gamma>0)$. This is, as in Velde et al. (1999), a reduced form to model the fact that there are alternative uses to coins other than paying for goods in the economy. They describe a situation in which agents derive utility from consuming a good that is produced outside the economy and must be paid with metallic coins. ${ }^{9}{ }^{10} 11$ The economy begins with a proportion $M$ of agents holding one unit of money. These agents are equally distributed among agents of each type. $M$ is also the proportion of the population that is holding in inventory a unit of money at any moment in time. These agents will be called money holders.

\footnotetext{
${ }^{8}$ In fact, indivisibility of coins was historically one the main causes of shortages of currency. As Wallace and Zhou (1997) put it, "shortage observations can be explained by the fact that the available currency could not be divided into smaller units" (p. 556). See also Sargent and Velde (2002).

${ }^{9}$ To keep the amount of money constant, we suppose that there is also a good that is exported so that trade is balanced and coins are also flowing into the economy.

${ }^{10}$ Historical references give some credit to this story. In Australia, for instance, this is the period when a very strong prohibition of exporting coins, which apparently was the major cause of the existing currency shortage, was established (see Butlin, 1953). See also Cuadras-Morató and Rosés (1998), p.32-33 for a review of a similar example for the case of Catalonia during the XIXth century. Based on an analysis of the Canadian case, Redish (1984) attributes the specie scarcity more to the currency laws in use during the Colonial period (1796-1830) than to an external drain due to the finance of imports.

${ }^{11}$ Related with this, see Jin and Temzelides (2004). They study the coexistence of fiat money and credit in a model in which agents live in different locations, meet more frequently with residents of their own location and public record-keeping of agents' trading histories exists only at the local level. One of the main results of the paper is reminiscent of the assumption we maintain: while credit transactions may take place among neighbors who interact with high probability, only monetary transactions occur among agents who live far apart (and whose frequency of meetings is relatively low).
} 
There could also be credit in this economy. In some meetings (details will be provided below) some agents decide to produce to get in exchange a document (also denoted as note or IOU) issued by their trade counterparts. The former become creditors and the latter will be called debtors. This note is a contract by which the agent who issues it promises to pay one unit of some asset in the future. Nothing prevents the creditors from circulating this IOU in exchange for goods or other assets. An IOU is put out of circulation when the debtor repays her debt. ${ }^{12}$ In order to do this, the debtor must produce goods and exchange them for some asset in the production subperiod and, then, swap it for the IOU she issued in the past in the repayment subperiod. In order to make this possible, we assume that there is a centralized location where debtors and creditors can meet during the repayment period. Back in the production subperiod, agents who met in this centralized location have no way to find each other again. ${ }^{13}$ Notice that our setting allows that debt is used to repay debt, while $\operatorname{Li}$ (2001) assumes that only money or goods can be used to repay debt. Once the debt is considered repaid, the note is destroyed, and the debtor becomes producer. For now, producers will be characterized simply as those agents who do not hold money and are neither debtors nor creditors. In order to ensure that debt will always be repaid, we assume that all agents can coordinate to deny access to consumption to those debtors who have not repaid their debts. ${ }^{14}$ This sets a limit of one to the credit an agent can receive.

\footnotetext{
${ }^{12}$ To avoid possible confusions, we shall use the following convention: the debtor will be "she" and the creditor will be "he".

${ }^{13}$ For a somewhat similar model with two subperiods with very different environments, see Lagos and Wright (2004).
} 
There are not restrictions on the circulation of debt in this economy. Thus, creditors can use the IOU they have in inventory to trade. Before a debt is repaid, it could happen that a creditor passes the note to another agent who, in exchange, gives him a consumption good and/or a coin. That agent who buys the IOU becomes the new creditor. As we have assumed, when debtors eventually acquire an asset with which to repay the debt, they will always be able to contact with the agent who is holding the note during the repayment subperiod.

2.3. Potential trades. When a period of time $t$ starts all the agents belong to one of the following categories: money holders (hold money in inventory), creditors (hold an IOU in inventory), debtors (have issued an IOU and have not repaid it yet), and producers (the rest of agents). Throughout the paper, we will assume that the particular category to which each agent pertains is common knowledge. In particular, potential buyers who are paired with potential sellers can always distinguish between debtors and producers. The measure of agents who is in each of the previous states is, respectively, $M, P_{c}, P_{d}$, and $P_{p}$. Taking $M$ as given, and taking into account that $1-M=P_{c}+P_{d}+P_{p}$ and that, by definition, $P_{c}=P_{d}$, we can summarize the distribution of states of agents simply by $P_{c}$. Agents are randomly matched in pairs. In order to have trade, it is first necessary that there is single coincidence of wants (the producer produces what the consumer wants to buy). Given that this condition holds, the following are the possible situations in which production, trade and consumption take place.

\footnotetext{
${ }^{14}$ Alternatively, it could be assume that there exists a legal system that costlessly enforces repayment of debt, as in Diamond (1990).
} 
A debtor might want to produce and exchange whenever she is matched with an agent who holds an asset (money holders and creditors) with which she will be able to repay her debt. Debtors might also produce and exchange when they meet a producer. In this case the producer will issue an IOU to pay for the good. Once the debtors get one unit of an asset (money or IOU), they will enter the repayment subperiod and repay their debts. Notice that, since production takes place during the production subperiod and goods, which are perishable, cannot be carried into the repayment subperiod, the only way to repay a debt is with assets. In other words, it is not feasible to repay a debt with goods.

Producers may be willing to produce when they meet money holders who pay with money, creditors who pay with second hand debt and other producers who pay with a newly issued IOU. Creditors might want to use the notes they have in inventory to buy goods from both producers and debtors. If they meet money holders, they could sell their IOU in exchange for money. Assuming that creditors accept money to cancel debts means that holding coins has to be better than holding an IOU. This implies that money holders will only be willing to exchange money for an IOU if, on top of it, they get some amount of their consumption good. Any agent holding a note at the end of the production subperiod (creditor) will enter the repayment subperiod in which he could be given one unit of an asset as means of canceling the debt. This will depend on whether the debtor who issued the IOU he is holding has been able to produce and exchange in order to get that asset. These are all the possible exchanges in this economy. Debtors will never act as buyers, since they will be denied consumption until they have repaid their debts. Also, money holders and creditors will never exchange as producers, because there is a limit of one unit of assets they can hold in storage that they have 
already reached. The only exception to this is that creditors may be willing to exchange their notes plus some consumption goods in exchange for coins. Finally, both creditors and money holders will be assumed to never issue debt to pay for consumption goods. If they did, they would have an incentive to cancel their debt immediately with the assets they were holding in the first place and, consequently, the final outcome would be exactly the same. This means that we do not need to worry about the possibility of credit chains (i.e., an agent being creditor and debtor at a time) developing in this economy.

Notice that money holders are the only group of agents who will never produce in this economy. In this particular sense, we can interpret the parameter $1-M$ as a measure of the extent with which an agent will meet exchange opportunities in the market.

2.4. Bargaining and Value functions. The terms of trade, that is, the number of units of good that change hands in each trade, are determined by a bargaining process between buyers and sellers in which we will assume that buyers make take-it-or-leave-it offers (TIOLIO). Thus, every time there is a possibility of trade, the buyer proposes an amount of goods that make the seller indifferent between producing or not. This simply means that the buyers get the whole surplus generated by trade. Let $q_{h j}$ be the amount of units of a consumption good exchanged when $h$ is the buyer and $j$ acts as the seller $(h, j=p, m, c, d)$. The subscripts $p, m, c$, and $d$ stand for, respectively, producer, money holder, creditor, and debtor. Table 1 summarizes the previous discussion on potential trades and terms of trade. 
Table 1. Exchange Patterns

\begin{tabular}{|l|c|c|c|c|c|}
\hline \multicolumn{7}{|c|}{ AGENT WHO PRODUCES } \\
\hline \multirow{4}{*}{} & & PRODUCER & CREDITOR & DEBTOR & MONEY \\
\cline { 3 - 7 } & & & & & HOLDER \\
\cline { 2 - 7 } AGENT & PRODUCER & $q_{p p}$ & $*$ & $q_{p d}$ & $*$ \\
\cline { 2 - 7 } CONSUMES & CREDITOR & $q_{c p}$ & $*$ & $q_{c d}$ & $*$ \\
\cline { 2 - 7 } & DEBTOR & $*$ & $*$ & $*$ & $*$ \\
\cline { 2 - 7 } & MONEY & & & & $*$ \\
\hline
\end{tabular}

* denotes that no trade takes place in the meeting

$q_{h j}$ denotes the amount of goods produced and exchanged in each of the meetings

Next, we define $V_{k}(k=p, m, c, d)$ as the expected discounted lifetime utility from beginning a period in state $k$, and let $V_{s c}$ be the value of entering the repayment period as a creditor. Let $\lambda_{h j}$ be the probability that a buyer $h$ wants to buy from a seller $j$. The following Bellman equations for producers, debtors, creditors, and money holders summarize the previous discussion about the trades that could take place in this economy. Without loss of generality we shall assume $\beta / N=1$.

\section{PRODUCER}

$$
\begin{aligned}
& r V_{p}=M \lambda_{m p}\left(-q_{m p}+V_{m}-V_{p}\right)+P_{p} \max _{\lambda_{p p}} \lambda_{p p}\left\lfloor u\left(q_{p p}\right)+V_{d}-V_{p}\right\rfloor+P_{p} \lambda_{p p}\left(-q_{p p}+V_{c}-V_{p}\right)+ \\
& +P_{c} \lambda_{c p}\left(-q_{c p}+V_{s c}-V_{p}\right)+P_{d} \max _{\lambda_{p d}} \lambda_{p d}\left[u\left(q_{p d}\right)+V_{d}-V_{p}\right]
\end{aligned}
$$

\section{DEBTOR}




$$
r V_{d}=M \lambda_{m d}\left(-q_{m d}+V_{p}-V_{d}\right)+P_{p} \lambda_{p d}\left(-q_{p d}+V_{p}-V_{d}\right)+P_{c} \lambda_{c d}\left(-q_{c d}+V_{p}-V_{d}\right)
$$

\section{CREDITOR}

$$
\begin{aligned}
& r V_{c}=M\left[\lambda_{m c}\left(-q_{m c}+V_{m}-V_{c}\right)+\left(1-\lambda_{m c}\right)\left(V_{s c}-V_{c}\right)\right]+P_{p}\left\{\max _{\lambda_{c p}}\left\{\lambda_{c p}\left[u\left(q_{c p}\right)+V_{p}-V_{c}\right]+\left(1-\lambda_{c p}\right)\left(V_{s c}-V_{c}\right)\right\}\right\}+ \\
& P_{d}\left\{\max _{\lambda_{c d}}\left\{\lambda_{c d}\left[u\left(q_{c d}\right)+V_{p}-V_{c}\right]+\left(1-\lambda_{c d}\right)\left(V_{s c}-V_{c}\right\}\right\}+P_{c}\left(V_{s c}-V_{c}\right)\right.
\end{aligned}
$$

\section{MONEY HOLDER}

$$
\begin{aligned}
& r V_{m}=\gamma+P_{p} \max _{\lambda_{m p}} \lambda_{m p}\left|u\left(q_{m p}\right)+V_{p}-V_{m}\right|+P_{d} \max _{\lambda_{m d}} \lambda_{m d}\left|u\left(q_{m d}\right)+V_{p}-V_{m}\right|+ \\
& P_{c} \max _{\lambda_{m c}}\left[u\left(q_{m c}\right)+V_{s c}-V_{m}\right]
\end{aligned}
$$

and $V_{s c}=M \lambda_{m d} V_{m}+\left(1-M \lambda_{m d}\right) V_{c}$

Expression (1), for instance, means the following. A producer meets an agent who is willing to consume her production good (single coincidence of wants) with probability $1 / N$. Then, with probability $M \lambda_{m p}$ she meets a money holder who is willing to exchange his cash for the good she produces. Her payoff in this case would be $q_{m p}+V_{m}$. With probability $P_{p} \lambda_{p p}$, she meets another producer who is willing to take her production good in exchange for a newly issued IOU. The payoff is now $-q_{p p}+V_{c}$. Similarly, with probability $P_{c} \lambda_{c p}$ she meets a creditor who is willing to take her production good in exchange for an IOU he got from a previous trade, resulting in a payoff $-q_{c p}+V_{s c}$. Also, a producer meets an agent who produces her consumption good with probability $1 / N$. If it is a producer (with probability $P_{p}$ ), then she has to decide whether to accept that good, consume it and become a debtor (the payoff is $u\left(q_{p p}\right)+V_{d}$ ). It could also be a debtor (with probability $P_{d}$ ). The decision to be taken then is analogous, and the payoff $u\left(q_{p d}\right)+V_{d}$. The rest of possible encounters would not result in 
any trade for the producer. The other expressions can be interpreted in a very similar fashion.

The TIOLIO assumption gives us the following terms of trade, which will simplify the previous Bellman equations:

(6) $q_{m d}=q_{p d}=q_{c d}=q_{d}=V_{p^{-}} V_{d}$

(7) $q_{m p}=V_{m}-V_{p}$

(8) $q_{p p}=V_{c^{-}} V_{p}$

(9) $q_{c p}=V_{s c^{-}} V_{p}$

(10) $q_{m c}=V_{m}-V_{s c}$

The meaning of these expressions should be obvious. For instance, expression (6) means that debtors are indifferent between producing in exchange for assets, repaying their debts and becoming producers $\left(-q_{d}+V_{p}\right)$ or continue as debtors $\left(V_{d}\right)$. Similar arguments apply to the rest of the expressions.

Notice that (6) and (2) imply that $V_{d}=0$ and, hence, $V_{p}=q_{d}$. Then, substituting in (7) and (8), $V_{m}=q_{m p}+q_{d}$ and $V_{c}=q_{p p}+q_{d}$. Also, $q_{c p}=M \lambda_{m d} q_{m p}+\left(1-M \lambda_{m d}\right) q_{p p}$ and $q_{m c}=(1-$ $\left.M \lambda_{m d}\right)\left(q_{m p}-q_{p p}\right)$. If we assume that creditors accept to be repaid with money, then $V_{m} \geq V_{c}$. This implies that $q_{m p} \geq q_{p p}$, which in turn means $q_{m c} \geq 0$ and $q_{m p} \geq q_{c p} \geq q_{p p}$. The former inequality signifies that creditors will be willing to produce positive amounts of goods to acquire money. The latter means that buying with one unit of money is cheaper than buying with an old note, which in turn is cheaper than buying with a newly issued note. 
Thus, nobody who has money has any interest in issuing debt. Also, old debt sells at a premium with respect to newly issued debt. ${ }^{15}$

2.5. Incentive compatibility conditions. Under the TIOLIO assumption, wouldbe producers are always given offers that make them indifferent between producing or not. It is buyers who make the exchange decision. Buyers will only be willing to carry out the trade if they get a positive surplus out of it. This can be expressed in the form of the following incentive compatibility conditions.

$$
\lambda_{m p}= \begin{cases}1 & \text { iff } \quad u\left(q_{m p}\right) \geq q_{m p} \\ 0 & \text { otherwise }\end{cases}
$$

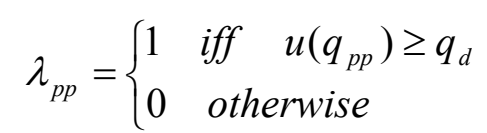

$$
\lambda_{p d}= \begin{cases}1 & \text { iff } \quad u\left(q_{d}\right) \geq q_{d} \\ 0 & \text { otherwise }\end{cases}
$$

$$
\lambda_{m d}= \begin{cases}1 & \text { iff } \quad u\left(q_{d}\right) \geq q_{m p} \\ 0 & \text { otherwise }\end{cases}
$$

$$
\lambda_{m c}=\left\{\begin{array}{l}
1 \quad \text { iff } u\left\lfloor\left(1-M \lambda_{m d}\right)\left(q_{m p}-q_{p p}\right)\right\rfloor \geq\left(1-M \lambda_{m d}\right)\left(q_{m p}-q_{p p}\right) \\
0 \quad \text { otherwise }
\end{array}\right.
$$

$$
\lambda_{c p}=\left\{\begin{array}{l}
1 \quad \text { iff } u\left|M \lambda_{m d} q_{m p}+\left(1-M \lambda_{m d}\right) q_{p p}\right| \geq M \lambda_{m d} q_{m p}+\left(1-M \lambda_{m d}\right) q_{p p} \\
0 \quad \text { otherwise }
\end{array}\right.
$$

$$
\lambda_{c d}=\left\{\begin{array}{l}
1 \quad \text { iff } u\left(q_{d}\right) \geq M \lambda_{m d} q_{m p}+\left(1-M \lambda_{m d}\right) q_{p p} \\
0 \quad \text { otherwise }
\end{array}\right.
$$

\footnotetext{
${ }^{15}$ This is largely an artifact of the assumptions on the timing of the model. Old debt can always be repaid in the immediate repayment subperiod if debtors get assets with which to do it. New debt, instead, will never be paid sooner than in the next period if the debtors can get then the assets with which they can settle the contract.
} 
Expression (11) (similarly for the rest of incentive compatibility conditions) means that money holders are willing to buy from producers if the utility they get from consuming $q_{m p}$ plus the value of becoming producers $\left[u\left(q_{m p}\right)+V_{p}=u\left(q_{m p}\right)+q_{d}\right]$ is at least as big as the value of holding one unit of money $\left(V_{m}=q_{m p}+q_{d}\right)$.

\section{Equilibrium}

The steady-state distribution of this economy, $P_{c}$, is described by the following equations:

$$
\begin{aligned}
& 1-M=P_{c}+P_{d}+P_{p} \\
& P_{c}=P_{d} \\
& P_{d}\left(M \lambda_{m d}+P_{c} \lambda_{c d}+P_{p} \lambda_{p d}\right)=P_{p}\left(P_{p} \lambda_{p p}+P_{d} \lambda_{p d}\right)
\end{aligned}
$$

Equations (18) and (19) are identities. Equation (20) simply equates the outflows from the debtor state to the inflows into it. As it should be clear, the $\lambda$ 's suffice to determine the steady-state.

The main concern of the paper will be the analysis of pure-strategy equilibria. For reasons of simplicity, we will not refer to mixed-strategy equilibria.

Definition of equilibrium. A pure-strategy equilibrium is a pair $\left(\lambda_{h j}, q_{h j}\right)$ that satisfies the Bellman equations (1)-(5), the terms of trade (6)-(10), and the incentive compatibility conditions (11)-(17). 
There are two broad classes of equilibria. First, we shall define the No-Trade Equilibrium, characterized by the fact that agents do not exchange with each other (autarky). This is defined as an equilibrium in which $\lambda_{p p}=\lambda_{m p}=0$. Trade Equilibria happen whenever $\lambda_{p p}$ and/or $\lambda_{m p}$ are different from zero. Agents in this kind of equilibria are able to produce, trade and consume thanks to the circulation of money and/or notes as media of exchange. In order to characterize these different equilibria we will proceed as follows: given $\lambda_{h j}$ and the corresponding $P_{c}$, solve the Bellman equations (1)-(5) for $q_{h j}$ and check the values of the parameters for which the incentive compatibility conditions (11)-(17) hold. For those parameter values, $\left(\lambda_{h j}, q_{h j}\right)$ constitutes an equilibrium.

We will first describe the No-Trade Equilibrium (Equilibrium N). Let $\lambda_{p p}=\lambda_{m p}=0$. Neither money, nor credit circulates in this economy. It is straightforward to prove the following lemma.

Lemma 1. For all $M \in(0,1)$ Equilibrium $N$ exists iff $\gamma / r>q^{*} \cdot{ }^{16}$

The intuitions for this result are clear: if the utility stream generated by the possession of money is high enough, money holders will never want to give money away and, consequently, it will be impossible to have money that circulates in this economy. On its part, the absence of credit in the economy is a self-fulfilling phenomenon. If agents think that debt will not be repaid, then nobody will engage in a debt contract in the first place. 
Let us now describe the Trade Equilibria. We shall begin with equilibria in which $\lambda_{m p}=1$, and, consequently, there is money circulating as medium of exchange. First of all, there is an equilibrium in which there is not credit circulating $\left(\lambda_{p p}=0\right)$ together with money (Equilibrium ME). While the reason for not having credit is exactly the same as before, the feature that allows money to be an active medium of exchange is that now the utility stream derived from the possession of money is relatively small and, consequently, now money holders are willing to spend it to acquire valuable consumption goods. The following lemma establishes this result.

Lemma 2. For all $M \in(0,1)$, Equilibrium $M E$ exists iff $\gamma / r<q^{*}$.

The next possibilities we want to examine are those in which, together with monetary exchange $\left(\lambda_{m p}=1\right)$, there exists the possibility of buying goods with credit $\left(\lambda_{p p}=1\right)$. The following lemma will be very useful to characterize these equilibria with credit.

Lemma 3. Given $\lambda_{p p}=\lambda_{c p}=\lambda_{p d}=\lambda_{c d}=1$ and $\lambda_{m d}=0$, there exist an equilibrium in which $q_{p p}<q_{d}<q^{*}$, provided that $r$ and $M$ are not too big.

Proof. Substituting for the values of $\lambda$ 's in equations (18)-(20), we can establish the result that $P_{c}=P_{d}=P_{p}=(1-M) / 3$. The Bellman equations (1) and (3) can now be written as:

\footnotetext{
${ }^{16}$ Proofs of most of all the lemmas in this section are relegated to the Appendix.
} 


$$
\begin{aligned}
& r q_{d}=\frac{1-M}{3}\left[u\left(q_{p p}\right)-q_{d}+u\left(q_{d}\right)-q_{d}\right] \\
& r\left(q_{d}+q_{p p}\right)=\frac{1-M}{3}\left[u\left(q_{p p}\right)-q_{p p}+u\left(q_{d}\right)-q_{p p}\right]
\end{aligned}
$$

From (21) and (22) we have

$q_{p p}=\frac{2(1-M)}{3 r+2(1-M)} q_{d}$, which substituted in (21) gives us the following

$$
\mathrm{A}\left(q_{d}\right)=r q_{d}-\frac{1-M}{3}\left\{u\left[\frac{2(1-M)}{3 r+2(1-M)} q_{d}\right]-q_{d}+u\left(q_{d}\right)-q_{d}\right\}=0
$$

Clearly,

$$
\begin{aligned}
& \mathrm{A}(0)=0, \mathrm{~A}\left(q^{*}\right)=r q^{*}-\frac{1-M}{3}\left\{u\left[\frac{2(1-M)}{3 r+2(1-M)} q^{*}\right]-q^{*}\right\}>0, \quad \text { and } \\
& \left.\frac{\partial \mathrm{A}}{\partial q_{d}}\right|_{q_{d}=0}<0
\end{aligned}
$$

This means that there exist $q_{d}, q_{p p}$ such that $0<q_{p p}<q_{d}<q^{*}$.

Notice that $\lambda_{p p}=1$ is satisfied iff $u\left(q_{p p}\right)>q_{d}$, which means that $u\left[\frac{2(1-M)}{2(1-M)+3 r} q_{d}\right]>q_{d}$. This is not true if either $r$ or $M$ have very large values.

Notice that $q_{d}$ and $q_{p p}$ are the solutions of a system of equations formed by (21) and (22). Their value depends exclusively on $r$ and $M$. This is a system of non-linear equations and we cannot get closed form solutions for the values of the unknowns. The lemma, however, guarantees that these solutions exist.

To be clear about the intuition of these results, we could ask why $r$ and $M$ cannot be too big to ensure that there is credit. That $r$ is not too big means that agents are not 
very impatient (i.e. they do not discount the future a lot). This is important for agents to agree to buy on credit that has to be returned later. Notice that if $r=0$, then $q_{p p}=q_{d}$. The bigger $r$ is, the bigger is $q_{d}$ relative to $q_{p p}$, or in other words, the bigger is the cost of repayment of debts compared with the amount of goods one can buy on credit. Once $q_{d}$ got a lot bigger than $q_{p p}$, nobody wants to buy on credit. What about $M$ ? If $M$ is big, agents do not want to buy on credit. The reason for this is that if $M$ is very big, then $q_{p p}$ is very small (in the limit when $M=1, q_{p p}=0$ ). Remember that $q_{p p}$ is the amount that makes the seller indifferent between producing and selling for a note or not, $q_{p p}=V_{c^{-}} V_{p}$. This is a small amount when $M$ is big because in that case producers may have, as alternative, a lot of potential money holders to whom they can sell if $\lambda_{m p}=1$ and, besides, because the value of becoming a creditor, $V_{c}$, is small because the producers or debtors to whom the note can be passed are very few and, moreover, eventual repayment of the debt will never take place with money (this is because $\lambda_{m d}=0$ ).

Our next task will be to find which of the possible combinations of $\lambda$ 's may constitute equilibrium. Clearly, $\lambda_{m p}=1$ (and, consequently, $q^{*}>q_{m p}$ ) implies $\lambda_{m c}=1$ (see (15)) and $\lambda_{c p}=1$ (see (16)). Suppose $\lambda_{p d}=0$. Then, $q^{*}<q_{d}$ (see (13)). Given the results from Lemma 3, $q_{d}>u\left(q_{p p}\right)>q_{p p}$, which is a contradiction with our assumption $\lambda_{p p}=1$. This means that if $\lambda_{p p}=1$, then $\lambda_{p d}=1$. In words, this means that if producers are willing to issue an IOU to buy from other producers an amount $q_{p p}$, they should also be willing to issue an IOU to buy from debtors a larger amount of goods $q_{d}$. This is quite an intuitive result. Notice that, for a debtor, the alternative to produce is to stay as a debtor, which has zero value $\left(V_{d}=0\right)$. For a producer the alternative is to stay as a producer, which has a positive value. Under TIOLIO, the amount produced by debtors that leaves 
them indifferent between producing and not producing, $q_{d}$, will be bigger than the amount produced by the producers, $q_{p p}$. Finally, suppose $\lambda_{m d}=1$. This implies that $\lambda_{c d}=1$ (see (14) and (17)). Thus, we have $\lambda_{m p}=\lambda_{p p}=\lambda_{m c}=\lambda_{c p}=\lambda_{p d}=\lambda_{m d}=\lambda_{c d}=1$. This is an equilibrium in which there is complete circulation of money and credit (that is, coins and notes always buy goods and also coins buy IOUs from creditors). This will be denoted as Equilibrium MC(1).

Suppose now that $\lambda_{m d}=0$ and $\lambda_{c d}=1$. We then have an equilibrium defined by $\lambda_{m p}=\lambda_{p p}=\lambda_{m c}=\lambda_{c p}=\lambda_{p d}=\lambda_{c d}=1$ and $\lambda_{m d}=0$. This is an equilibrium in which notes always buy goods. Money, though, has a more restricted circulation, because money holders do not buy goods from debtors $\left(\lambda_{m d}=0\right)$. Notice that in this equilibrium, necessarily $q_{m p}>q_{d}$. What happens in this case is that $q_{d}$ is relatively small, so that money holders will not spend their coins buying from debtors. This will be called Equilibrium MC(2).

To extinguish the possibilities of equilibria when $\lambda_{m p}=\lambda_{p p}=1$, let us suppose that $\lambda_{m d}=0$ and $\lambda_{c d}=0$. This means that $q_{p p}>u\left(q_{d}\right)$. Also, from Lemma 3, $q_{d}>q_{p p}$. But this is contradictory with $\lambda_{p d}=1$. Intuitively, it is easy to explain why this is so: if the producers buy from a debtor, then the creditors should also buy from a debtor. This is because the opportunity cost is identical in both cases, $q_{p p}=q_{c p}$. Summing up, no equilibrium other than $M C(1)$ and $M C(2)$ exists in which both money and IOUs buy goods.

Within the category of trade equilibria, let us look now into the possibility of $\lambda_{m p}=0$ and $\lambda_{p p}=1$ (money does not buy goods from producers, but credit does). If we 
suppose that $\lambda_{p d}=1$, then this, together with $\lambda_{m p}=0$, implies that $u\left(q_{d}\right)<q_{m p}$, so $\lambda_{m d}=0$. Next, we suppose $\lambda_{c d}=1$. This means that $u\left(q_{d}\right)>q_{p p}$. Then, necessarily, $q^{*}>q_{p p}$ and $u\left(q_{p p}\right)>q_{p p}$, which means that $\lambda_{c p}=1$. If we finally suppose that $\lambda_{m c}=1$, then we have an equilibrium in which $\lambda_{m p}=\lambda_{m d}=0$ and $\lambda_{p p}=\lambda_{p d}=\lambda_{c d}=\lambda_{c p}=\lambda_{m c}=1$. This is Equilibrium $C M$. It is characterized by the fact that credit circulates completely and money circulates only because money holders accept to exchange money for an IOU. Notice that in this equilibrium money acts only as a settlement device of credit contracts.

What happens if we suppose $\lambda_{m c}=0$ instead? The new equilibrium can be described by $\lambda_{m p}=\lambda_{m d}=\lambda_{m c}=0$ and $\lambda_{p p}=\lambda_{p d}=\lambda_{c d}=\lambda_{c p}=1$. This is called Equilibrium $C$. Only credit circulates in this equilibrium. Money holders are never willing to give away coins in exchange for either goods or other assets.

This completes the catalogue of possible equilibria of this model. In order to see that there are no other possibilities, let us see what happen when we assume differently than above. For instance, given $\lambda_{m p}=0, \lambda_{p p}=1$ and $\lambda_{p d}=1$, let us suppose that $\lambda_{c p}=0$ (so $\left.q_{p p}>q^{*}\right)$. Then, clearly $q_{p p}>u\left(q_{d}\right)$ which implies that $\lambda_{c d}=0$. But then, by (3), $V_{c}=0$ and if the value of being a creditor is zero, it does not make any sense to incur in a cost $-q_{p p}$ to change from being a producer to being a creditor (by TIOLIO $-q_{p p}+V_{c^{-}} V_{p}=0$ ). Producers would only accept to produce in exchange for credit if $q_{p p}<0$, that is, if instead of incurring a cost of production they were given a production subsidy. This cannot be equilibrium. 
If we suppose $\lambda_{c d}=0$ and $\lambda_{c p}=1$, from the Bellman equations (1) and (3) we have

$$
\begin{aligned}
& r q_{d}=P_{p}\left\lfloor u\left(q_{p p}\right)-q_{d}\right\rfloor+P_{d}\left[u\left(q_{d}\right)-q_{d}\right] \\
& r\left(q_{p p}+q_{d}\right)=P_{p}\left[u\left(q_{p p}\right)-q_{p p}\right]
\end{aligned}
$$

Operating, we get $r q_{p p}+P_{d}\left[u\left(q_{d}\right)-q_{d}\right]=P_{p}\left\lfloor q_{d}-q_{p p}\right\rfloor$, which, since $\lambda_{p d}=1$, is positive. This means that $q_{d}>q_{p p}$ and also $u\left(q_{d}\right)>q_{p p}$. This, however, contradicts $\lambda_{c d}=0$. Hence, this is not equilibrium. Finally, given $\lambda_{m p}=0$ and $\lambda_{p p}=1$, let us suppose $\lambda_{p d}=0$. Then $q_{p p}>q_{d}>q^{*}$. This implies $u\left(q_{d}\right)<q_{m p}$ and, consequently, $\lambda_{m d}=0$. Also $\lambda_{c p}=0$ and $\lambda_{c d}=0$. By (3), this means $V_{c}=0$ and, as we have seen above, this is incompatible with an equilibrium in which $\lambda_{p p}=1$.

The previous discussion will be summarized in the following proposition:

Proposition 1. Only the following equilibria may exist in this economy:

- Equilibrium $N$ : $\lambda_{m p}=0$ and $\lambda_{p p}=0$.

- Equilibrium ME: $\lambda_{m p}=1$ and $\lambda_{p p}=0$.

- Equilibrium $M C(1): \lambda_{m p}=\lambda_{p p}=\lambda_{m c}=\lambda_{c p}=\lambda_{p d}=\lambda_{m d}=\lambda_{c d}=1$

- Equilibrium $M C(2): \lambda_{m d}=0$ and $\lambda_{m p}=\lambda_{p p}=\lambda_{m c}=\lambda_{c p}=\lambda_{p d}=\lambda_{c d}=1$.

- Equilibrium CM: $\lambda_{m p}=\lambda_{m d}=0$ and $\lambda_{p p}=\lambda_{p d}=\lambda_{c d}=\lambda_{c p}=\lambda_{m c}=1$.

- Equilibrium $C: \lambda_{m p}=\lambda_{m d}=\lambda_{m c}=0$ and $\lambda_{p p}=\lambda_{p d}=\lambda_{c d}=\lambda_{c p}=1$.

We are now ready to present a few more results that define the parameter space for which the different equilibria exist. 
Lemma 4. Provided that $r$ and $M$ are not too big, Equilibrium $C$ exists iff $\gamma / r>q^{*}+q_{p p}(r, M)+q_{d}(r, M)$.

Lemma 5. Provided that $r$ and $M$ are not too big, $\frac{\gamma}{r}>q^{*}+q_{d}(r, M)-\frac{1-M}{3 r}\left\{u\left[q^{*}-q_{p p}(r, M)\right]-q^{*}+q_{p p}(r, M)\right\} \quad \quad$ and $\frac{\gamma}{r}<q^{*}+q_{d}(r, M)+q_{p p}(r, M)$ are necessary conditions for existence of Equilibrium $C M$.

Although the conditions given in the previous lemma are not sufficient, it is possible to check numerically that the equilibrium $C M$ exists for all the points of the parameter space defined by them. Also notice that equilibria $C$ and $C M$ will not coexist for any values of the parameters.

Lemma 6. $\quad$ Equilibrium $\quad M C(2) \quad$ exists iff $\frac{\gamma}{r}<q^{*}+q_{d}(r, M)-\frac{1-M}{3 r}\left\{u\left[q^{*}-q_{p p}(r, M)\right]-q^{*}+q_{p p}(r, M)\right\} \quad$ for $\quad$ values $\quad$ of $\quad$ the parameters such that $r$ and $M$ are not too big.

Notice that if agents are very impatient, that is, $r$ is very big, then money holders will prefer to buy goods from debtors than waiting for better deals to come. This is so even if debtors produce a relatively little amount in exchange for a unit of money. Similarly, if $M$ is very big, then the chances for money holders to find valuable exchange opportunities to spend their money are very scarce and, consequently, they 
will also be willing to buy goods from debtors (even though the amount of goods they get from those is relatively small).

All that is left to have a complete characterization of the existence of equilibrium is to define the region of the parameter space for which equilibrium $M C(1)$ exists. Due to the particular form that the Bellman equations (1)-(5) take in this equilibrium, it is very cumbersome to find analytical expressions for this and, consequently, we revert to numerical examples. Intuitively, equilibrium $M C(1)$ should be confined to a region of the parameter space $(\gamma, M)$ placed in the southeast of Figure 1 (which was drawn for values of $r=0.01$ and a quadratic utility function). For instance, it can be shown that equilibrium $M C(1)$ exists for values of the parameters $r=0.01$, $\gamma=0.002$, and $M=0.98$. Notice that, given a particular value of $r$, this equilibrium exists for particularly high values of $M$, precisely the values for which equilibrium $M C(2)$ can be shown not to exist.

All these existence results can be summarized in the following proposition (and Figure 1).

Proposition 2. Provided that $r$ and $M$ are not too big, we can state the following results: a) Equilibrium $N$ exists for values of the parameters such that $\gamma / r>q^{*} ;$ b) Equilibrium $M E$ exists for values of the parameters such that $\gamma / r<q^{*}$; c) Equilibrium $C$ exists for values of the parameters such that $\gamma / r>q^{*}+q_{d}(r, M)+q_{p p}(r, M)$; d) Equilibrium $C M$ exists for values of the parameters such that $q^{*}+q_{d}(r, M)+q_{p p}(r, M)>\frac{\gamma}{r}>q^{*}+q_{d}(r, M)-\frac{1-M}{3 r}\left\{u\left[q^{*}-q_{p p}(r, M)\right]-q^{*}+q_{p p}(r, M)\right\}$, 
d) Equilibrium $M C(2)$ exists for values of the parameters such that $\frac{\gamma}{r}>q^{*}+q_{d}(r, M)-\frac{1-M}{3 r}\left\{u\left[q^{*}-q_{p p}(r, M)\right]-q^{*}+q_{p p}(r, M)\right\} ;$ e) Equilibrium $M C(1)$ exists for values of the parameters placed in the southeast corner of the parameter space drawn in Figure 1 (for instance, Equilibrium $M C(1)$ exists for values of the parameters $r=0.01, \gamma=0.002$, and $M=0.98$ ); and f) these are the only equilibria of the model $\left[q_{d}(r, M)\right.$ and $q_{p p}(r, M)$ are the solutions to the system of equations (21) and (22)].

\section{[PLACE FIGURE 1 HERE]}

In the model a shortage of coins corresponds to a situation in which money holders do not spend their coins to buy either goods or notes and rather keep them. The different equilibria of the model can be characterized by an index $s=\frac{p_{p} \lambda_{m p}+p_{c} \lambda_{m c}+p_{d} \lambda_{m d}}{1-M}$ that measures the incidence of currency shortages. For the different equilibria of the model is easy to show that, from more to less acute degree of shortage the value of $s$ is $s_{N}=s_{C}=0, s_{C M}=1 / 3, s_{M C(2)}=2 / 3$, and $s_{M E}=s_{M C(1)}=1$. In other words, equilibria $N$ and $C$ correspond to situations in which coins do not circulate at all, equilibria $M E$ and $M C(1)$ to situations in which money holders are always willing to spend their coins to buy consumption goods and notes and, finally, equilibria $C M$ and $M C(2)$ correspond to intermediate situations.

It is interesting to discuss existence of the different equilibria and their characteristics in relation to the two parameters plotted in Figure 1: the intrinsic value of money, $\gamma$, and the amount of money holders in the economy, $M$. The latter is, by no 
means, equivalent to the amount of money that actually circulates in the economy. For our purposes, it is convenient to interpret $M$ as the absence of exchange opportunities in the economy, since the higher is the number of money holders, the lower will be the likelihood of meeting someone from whom to get goods (producers and debtors) or goods and notes (creditors).

Figure 1 shows that there are two different types of equilibria for all values of the parameter space: one of them without credit (for small values of $\gamma, M E$, and for higher values of $\gamma, N)$; and the other one with notes circulating $(C, C M, M C(2)$ or $M C(1))$. Thus, the first aspect we want to emphasize is that credit emerges as a purely self-fulfilling phenomenon in our model. After all, the existence and circulation of credit only depends on the fact that agents believe that this credit will be accepted by others and, eventually, repaid. Consequently, there exist some equilibrium in which credit circulates for all values of the parameters. This contrasts with the results obtained in Shi (1996) and Li (2001). In these papers a monetary equilibrium with credit exists only when the parameter $M$ is high enough. The reason for this result is their common assumption that money is the only way to repay debts. As a consequence, credit only appears if the proportion of agents who hold money is high enough.

Second, when credit does not emerge in this economy, the parameter space can be divided into two well-defined regions. For high enough values of $\gamma\left(\gamma>r q^{*}\right)$ commodity money is very valuable and does not circulate because money holders prefer to keep it. The only equilibria in this case is $N$ (autarky). In this situation there is a serious shortage of coins because money holders decide to keep them completely away from the internal market. This implies that, unless some form of credit appears, no 
exchange will take place at all. On the other hand, when the intrinsic value of money is low enough $(\gamma<r q$ ), the unique equilibrium is $M E$, in which the only media of exchange are coins. Obviously, there is not shortage of coins in this case and money holders are always willing to spend their currency for consumption goods, independently of the value of the parameter $M$. This equilibrium is identical to the monetary equilibrium without credit in Shi (1996) and Li (2001). Both papers deal with fiat money, which can be considered a particular case in our model when $\gamma=0$.

Finally we also analyze existence of all the equilibria with circulation of notes in the same parameter space $(\gamma, M)$. First, when $\gamma$ is very big, money holders do not spend money at all and the resulting equilibrium is always $C$. Notes are the only possible way of alleviating the currency shortage in this situation and the only alternative to this is the equilibrium without exchange, $N$. As $\gamma$ gets smaller the equilibrium will also depend on $M$. For values of $\gamma$ quite big, if $M$ is small, spending money to buy notes is the best strategy (equilibrium $C M$ ). The reasons for this are, first, that money holders get some amount of consumption good when they buy notes and, second, that there are still lots of exchange opportunities in the economy which can be taken advantage of if one is holding notes. For bigger values of $M$, though, it is better to keep the coins (equilibrium C) because the immediate reward of consumption does not compensate for the lack of exchange opportunities of those who hold notes. As $\gamma$ keeps going down, for relatively small values of $M$ the best strategy is still to buy notes with coins, but for bigger values of $M$ now the best money holders can do is to spend the money less selectively, buying both notes and goods from producers (equilibrium $M C(2)$ ). Notice the asymmetry in the appearance of currency shortages in the model: when the intrinsic value of money is 
relatively high, big $M$ means that it is a good idea to keep the money which then does not circulate. Since there are not good opportunities for exchange, holding money is the best strategy. When money is less valuable, however, a high value for $M$ gives incentives to money holders to spend it rapidly because they want to take advantage of the few exchange opportunities they encounter. Obviously, the degree of shortage of coins is lower in the latter case. Finally, when $\gamma$ is very small, we have three different regions depending on the values for $M$. For small values we have, as before, equilibrium $C M$. Notice that, as far as $M$ is low enough and there is credit in the economy, not matter how low the intrinsic value of coins is, they are never exchanged for consumption goods. For higher values of $M$ we have, as before, equilibrium $M C(2)$, so the coins are spent less selectively. Finally, for very high values of $M$ we have that money holders decide to spend their coins in all possible situations, so they buy notes and goods from producers as well as from debtors (equilibrium $M C(1)$ ). These three cases correspond, respectively, to progressively lower levels of coin shortages.

\section{Welfare}

The following lines present some welfare results derived from the model. The starting point is the definition of a welfare criterion: $W^{E}=V_{m}^{E} P_{m}^{E}+V_{p}^{E} P_{p}^{E}+V_{c}^{E} P_{c}^{E}+$ $V_{d}^{E} P_{d}^{E} . \quad(E=\{N, M E, C M, C, M C(1), M C(2)\})$. This variable measures the long-run expected utility of a representative agent, not conditional on her current state.

For values of the parameters such that $\gamma / r>q^{*}$, the existing equilibria can be ranked according to the welfare criterion. The main analytical result of this section is 
that the No-Trade Equilibrium $N$ has always a lower welfare than any other trade equilibria with which it coexists.

Proposition 3. If $\gamma / r>q^{*}, W^{N}<W^{C}, W^{C M}, W^{M C(2)}$

Proof. See Appendix.

The No-Trade Equilibrium is always dominated by any trade equilibrium with which it coexists. The presence of credit and the circulation of money improve the efficiency of any economy when comparing with the no-trade situation. Intuitively, the no-trade equilibrium is always dominated by any other equilibrium in which money holders do at least as well as in the no-trade equilibrium and the non-money holders see that some trade opportunities are created by the circulation of media of exchange (coins or notes).

On the other side, if $\gamma / r<q^{*}$, then no general analytical result can be presented but we can construct numerical results to illustrate the welfare implications of the model. It is easy to prove that $V_{m}^{M E}=\frac{\gamma}{r}+\frac{1-M}{r}\left[u\left(q_{m p}^{M E}\right)-q_{m p}^{M E}\right]$ and $V_{p}^{M E}=0$. Consequently, $W^{M E}=\frac{M \gamma}{r}+\frac{M(1-M)}{r}\left[u\left(q_{m p}^{M E}\right)-q_{m p}^{M E}\right]$. Clearly, non-money holders are better off in both equilibria $C M$ and $M C$ (2) (see Proof of Proposition 3). Money holders, however, are not unambiguously better off in those equilibria. Moreover, we cannot generally rank these equilibria in terms of $W$. 
Numerical examples, however, show that for most values of the parameters it is true that $W^{C M}, W^{M C(2)}, W^{M C(1)}>W^{M E}$. This means that for most values of the parameters, equilibria with circulation of notes is welfare superior to a situation in which credit does not exist and notes do not circulate. The only exceptions to this general rule are cases in which $M$ is very high. In those cases, the equilibrium without credit is better than the equilibria with credit. This is because credit displaces production opportunities, so the emergence of credit creates a trade-off because it allows more exchanges but, at the same time, reduces the number of producers with whom money holders can be paired (credit crowds out production). This outcome is due to the particular assumptions of the model, in particular the assumption of unitary inventories. ${ }^{17}$

These welfare results confirm that the existence of credit and the circulation of notes enhances welfare in almost all situations and, in that respect, are not different from those obtained in the models by Shi (1996) and Li (2001). This is not surprising, given that credit here is an efficient exchange mechanism that helps to overcome trade frictions and allows a larger amount of exchanges. We have to bear in mind, however, that our modeling strategy is extremely simple and assumes away from complications such as the possibility of default, asymmetries of information, notes of different quality, possibility of counterfeiting, etc. which would inevitably alter this result.

\section{Concluding remarks}

\footnotetext{
${ }^{17}$ A very similar result arises in $\mathrm{Li}$ (2001) for identical reasons.
} 
This paper provides a search theoretical monetary model that captures two phenomena that have jointly characterized several episodes of monetary history: currency shortages and the circulation of privately issued notes. As it is customary in this type of models, the media of exchange used by the agents to complete their economic transactions are determined as part of the equilibria. We provide the characterization of all the different equilibria of the model and specify the conditions under which there is a currency shortage and/or privately issued notes are used as means of payment. There is multiplicity of equilibria for all the values of the parameters, but some equilibrium in which notes circulate, either as the only medium of exchange or together with metal coins, always exist. Hence, credit is a self-fulfilling phenomenon that depends on the beliefs of agents about acceptability and future repayment of notes. The degree of circulation of coins depends on two crucial parameters, namely, the intrinsic utility of holding coins and the extent to which it is possible to find exchange opportunities in the market. If money is very valuable, then coins do not circulate and notes are the only possible way to alleviate trade frictions. As money becomes less valuable, the circulation of coins depends also on the trade opportunities available to the money holders. In general terms, the circulation of notes is shown to be welfare improving.

There are several obvious shortcomings of our analysis that surely deserve further research. For instance, we do not deal in this paper with the issue of asymmetries of information, which is crucial for the analysis of credit and the circulation of private notes. Another important subject we also leave aside of the analysis of the paper is the modeling of financial intermediaries. Although our model takes credit into consideration, it would be interesting to consider a different model in 
which trade frictions gave rise to an endogenous role for financial intermediation and consider how this would affect the circulation of private debt and currency. ${ }^{18}$

On a more general level, our research raises several questions that affect the historical interpretation of important macroeconomic relationships. First, there is the general question of which is the relevant definition of money supply for the historical period previous to the formation of modern Central Banks and monetary policy as we know them today. Second, and somehow related to the previous point, it is true that, although from a macroeconomic theory point of view, it seems clear that falling prices should alleviate a currency shortage, there is some evidence that at least in some economies, agents reacted also creating alternative media of exchange. This may be related to some notion of price rigidity that it is worth considering. It seems to us that this is an interesting subject that may deserve further research.

\section{Appendix}

Proof of Lemma 1. In Equilibrium $N, \lambda_{p p}=\lambda_{m p}=0$ and then $V_{p}=0$ and $V_{m}=q_{m p}=\gamma / r$. The incentive compatibility condition for $\lambda_{m p}$ to be zero implies that $q_{m p}>q^{*}$ and, consequently, equilibrium exists if $\gamma / r>q^{*}$.

\footnotetext{
${ }^{18}$ Cavalcanti and Wallace (1999) and Williamson (1999) are examples of search models with circulation of private banknotes. Freeman (1996) and Bullard and Smith (2003b) take on private banknotes in other modeling contexts.
} 
Proof of Lemma 2. In Equilibrium $M E, \lambda_{m p}=1$ and $\lambda_{p p}=0$ and $P_{p}=1-M$, and the Bellman equations (1)-(5) are easily summarized as:

$$
\begin{aligned}
& V_{p}=0 \\
& r V_{m}=\gamma+(1-M)\left[u\left(q_{m p}\right)-V_{m}\right]
\end{aligned}
$$

Since $V_{m}=q_{m p}$, then we can write

$$
\left.\Omega\left(q_{m p}\right)=r q_{m p}-\gamma-(1-M) \mid u\left(q_{m p}\right)-q_{m p}\right\rfloor=0
$$

Clearly, $\Omega(0)=-\gamma, \Omega\left(q^{*}\right)=r q^{*}-\gamma$ and $\left.\frac{\partial \Omega}{\partial q_{m p}}\right|_{q_{m p}=0}<0$. A unique equilibrium in which $q^{*}>q_{m p}>0$ exists iff $\Omega\left(q^{*}\right)=r q^{*}>\gamma$.

Proof of Lemma 4. Given the results from Lemma 3 and $\lambda_{m c}=\lambda_{m p}=0$, we can write the Bellman equation (4) as $\Psi\left(q_{m p}\right)=r\left[q_{m p}+q_{d}(r, M)\right]-\gamma=0$, where $q_{d}(r, M)$ is part of the solution of the system of equations (21) and (22). Clearly, $\Psi(0)<0$, and $\frac{\partial \Psi}{\partial q_{m p}}=r>0$. In order to have $q_{m p}>q^{*}$ we only need that $\Psi\left(q^{*}\right)=r\left[q^{*}+q_{d}(r, M)\right]-\gamma<0$ (A1). Next, we can check that $\lambda_{m c}=0$ iff $\gamma / r>q^{*}+q_{p p}(r, M)+q_{d}(r, M)$ (A2). Notice that the restriction (A1) holds whenever the restriction (A2) also holds.

Proof of Lemma 5. Given the results from Lemma 3, we can write the Bellman equation as

$$
\mathrm{Z}\left(q_{m p}\right)=r\left[q_{m p}+q_{d}(r, M)\right]-\gamma-\frac{1-M}{3}\left\{u\left[q_{m p}-q_{p p}(r, M)\right]-\left[q_{m p}-q_{p p}(r, M)\right]\right\}=0
$$

where $q_{d}(r, M)$ and $q_{p p}(r, M)$ are the solution of a system of equations formed by (21) and (22). It is easy to prove that $\frac{\partial \mathrm{Z}}{\partial q_{m p}}=r-\frac{1-M}{3}\left[\left(u^{\prime}-1\right)\right]>0$. Consequently, $Z\left(q^{*}\right)<0$ is a 
necessary and sufficient condition to have $q_{m p}>q^{*}$. This is equivalent to say $\frac{\gamma}{r}>q^{*}+q_{d}(r, M)-\frac{1-M}{3 r}\left\{u\left[q^{*}-q_{p p}(r, M)\right]-q^{*}+q_{p p}(r, M)\right\}$. Finally, if $\lambda_{m c}=1$, that is, $\quad q_{m p}^{C M}(\gamma, r, M)-q_{p p}(r, M)<q^{*}$ then it is easy to see that $\frac{\gamma}{r}<q^{*}+q_{d}(r, M)+q_{p p}(r, M)-\phi$ where $\phi=\frac{1-M}{3 r}\left\{u\left[q_{m p}^{M C}(\gamma, r, M)-q_{p p}(r, M)\right]-\left[q_{m p}^{M C}(\gamma, r, M)-q_{p p}(r, M)\right]\right\}>0$.

Consequently, a necessary condition for existence of equilibrium $C M$ is $\frac{\gamma}{r}<q^{*}+q_{d}(r, M)+q_{p p}(r, M)$

Proof of Lemma 6. Given the results from Lemma 3, we can write the Bellman equation (4) as $\Omega\left(q_{m p}\right)=r\left[q_{m p}+q_{d}(r, M)\right]-\gamma-\frac{1-M}{3}\left\{u\left(q_{m p}\right)-q_{m p}+u\left[q_{m p}-q_{p p}(r, M)\right]-\left[q_{m p}-q_{p p}(r, M)\right]\right\}=0$ where $q_{d}(r, M)$ and $q_{p p}(r, M)$ are the solution of a system of equations formed by (21) and (22). It is easy to prove that $\frac{\partial \Omega}{\partial q_{m p}}=r-\frac{1-M}{3}\left[2\left(u^{\prime}-1\right)\right]>0$. Consequently, $\Omega\left(q^{*}\right)>0$ is a necessary and sufficient condition to have $0<q_{m p}<q^{*}$. This is equivalent to say $\frac{\gamma}{r}<q^{*}+q_{d}(r, M)-\frac{1-M}{3 r}\left\{u\left[q^{*}-q_{p p}(r, M)\right]-q^{*}+q_{p p}(r, M)\right\}$. Finally, it must be that $\lambda_{m d}=0$. This means that $u\left[q_{p p} \frac{2(1-M)+3 r}{2(1-M)}\right]<q_{m p}$, which is true unless either $r$ or $M$ are very big. $\square$ 
Proof of Proposition 3. Rather trivially, $V_{m}^{N}=\frac{\gamma}{r}, V_{p}^{N}=0$, and $W^{N}=\frac{M \gamma}{r}$.

Moreover,

$V_{m}^{C}=\frac{\gamma}{r}, V_{p}^{C}=q_{d}, V_{c}^{C}=q_{p p}+q_{d}, V_{d}^{C}=0$, and $W^{C}=\frac{M \gamma}{r}+\frac{1-M}{3}\left(2 q_{d}+q_{p p}\right) . \quad$ Also,

$V_{m}^{C M}=\frac{\gamma}{r}+\frac{1-M}{3 r}\left[u\left(q_{m p}^{C M}-q_{p p}\right)-\left(q_{m p}^{C M}-q_{p p}\right)\right], V_{p}^{C M}=q_{d}, V_{c}^{C M}=q_{p p}+q_{d}, V_{d}^{C M}=0$,

and $W^{C M}=\frac{M \gamma}{r}+\frac{M(1-M)}{3 r}\left[u\left(q_{m p}^{C M}-q_{p p}\right)-\left(q_{m p}^{C M}-q_{p p}\right)\right]+\frac{1-M}{3}\left(2 q_{d}+q_{p p}\right)$.

Also,

$V_{m}^{M C(2)}=\frac{\gamma}{r}+\frac{1-M}{3 r}\left[u\left(q_{m p}^{M C(2)}\right)-q_{m p}^{M C(2)}+u\left(q_{m p}^{M C(2)}-q_{p p}\right)-\left(q_{m p}^{M C(2)}-q_{p p}\right)\right], V_{p}^{M C(2)}=q_{d}$,

$V_{c}^{M C(2)}=q_{p p}+q_{d}, V_{d}^{M C(2)}=0$, and $W^{M C(2)}=\frac{M \gamma}{r}+\frac{M(1-M)}{3 r} \times$

$\times\left[u\left(q_{m p}^{M C(2)}\right)-q_{m p}^{M C(2)}+u\left(q_{m p}^{M C(2)}-q_{p p}\right)-\left(q_{m p}^{M C(2)}-q_{p p}\right)\right]+\frac{1-M}{3}\left(2 q_{d}+q_{p p}\right)$.

It is immediate that $W_{m}^{N}<W_{m}^{C}, W_{m}^{C M}, W_{m}^{M C(2)}$.

\section{References}

Ashton (1945), T. S. "The Bill of Exchange and Private Banks in Lancashire, 1790-1830” Economic History Review, 15, pp.25-35.

Bernhardt, D. (1989) "Money and Loans" Review of Economic Studies, 56, pp.89-100.

Bullard, J. and B.D. Smith (2003a) "The value of inside and outside money" Journal of Monetary Economics, 50, pp.389-417.

Bullard, J. and B.D. Smith (2003b) "Intermediaries and payments instruments" Journal of Economic Theory, 109, pp.172-197. 
Butlin, S.J. (1953) Foundations of the Australian Monetary System (1788-1851)

$\begin{array}{llll}\text { Melbourne } & \text { Pniversity } & \text { Press. at }\end{array}$

$\underline{\text { http://purl.library.usyd.edu.au/setis/id/sup0003 }}$

Cameron, R. (1967) Banking in the Early Stages of Industrialization Oxford University Press.

Cavalcanti, R. and N. Wallace (1999) "A Model of Private Bank-note Issue" Review of Economic Dynamics, 2, pp.104-136.

Cuadras-Morató, X. and J. R. Rosés (1998) "Bills of exchange as money: sources of monetary supply during the industrialisation of Catalonia, 1844-74" Financial History Review, 5, pp.27-47.

Diamond, P. (1990) "Pairwise Credit in Search Equilibrium” Quarterly Journal of Economics, 105, pp.285-319.

Freeman, S. (1996) "Clearinghouse banks and banknote over-issue" Journal of Monetary Economics, 38, pp.101-115.

Hanson, J. R. (1979) "Money in the Colonial American Economy: an Extension” Economic Inquiry, 17, pp.281-286.

Jin, Y. and T. Temzelides (2004) "On the local interaction of money and credit" Review of Economic Dynamics, 7, pp.143-156.

Lagos, R. and R. Wright (2004) “A Unified Framework for Monetary Theory and Policy Analysis” Research Department Staff Report 346, Federal Reserve Bank of Minneapolis. Available at http://minneapolisfed.org/research/sr/sr346.html

Li Y. (2001) “A Search Model of Money and Circulating Private Debt with Applications to Monetary Policy” International Economic Review, 42, pp.925-946.

Murphy, A.E. (1978) "Money in an Economy without Banks: the case of Ireland" The Manchester School, 46, pp.41-50. 
Redish, A. (1984) "Why was Specie Scarce in Colonial Economies? An Analysis of the Canadian Currency, 1796-1830" Journal of Economic History, 44, pp.713-728.

Sargent T. J. and F. R. Velde (2002) The Big Problem of Small Change Princeton University Press.

Schumpeter, J. A. (1986) History of Economic Analysis Allen \& Unwin. London.

Shi, S. (1996) "Credit and Money in a Search Model with Divisible Commodities" Review of Economic Studies, 63, pp.627-652.

Townsend, R. (1989) "Currency and Credit in a Private Information Economy" Journal of Political Economy, 97, pp.1323-1344.

Townsend, R. and N. Wallace (1987) "Circulating Private Debt: An Example with a Coordination Problem" in E. C. Prescott and N. Wallace (eds.) Contractual Arrangements for Intertemporal Trade University of Minnesota Press.

Velde, F. R., W. E. Weber and R. Wright (1999) “A Model of Commodity Money with Applications to Gresham's Law and the Debasement Puzzle" Review of Economic Dynamics, 2, pp.291-323.

Wallace, N. and R. Zhou (1997) "A model of a currency shortage" Journal of Monetary Economics, 40, pp.555-572.

Williamson, S.D. (1999) "Private Money" Journal of Money, Credit and Banking, 31, pp.467-491. 
Figure 1. Equilibria for $r=0.01$ and quadratic utility

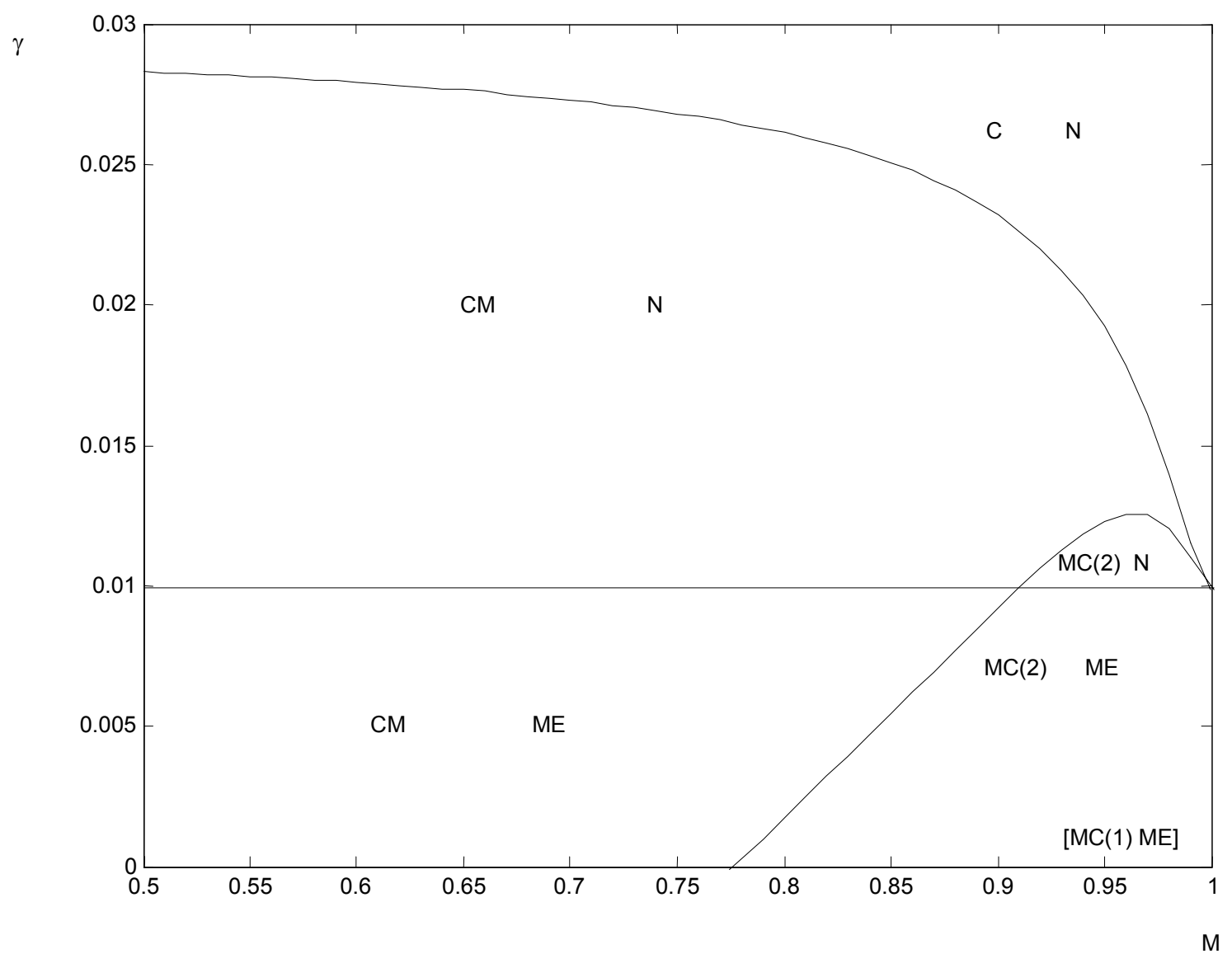

